\title{
Tuning Of Cost-231 hata Model For RADIO Wave Propagation Predictions
}

\author{
Chhaya Dalela $^{1}$, M V S N Prasad ${ }^{2}$, P K Dalela $^{3}$ \\ ${ }^{1}$ JSS Academy of Technical Education, C-20/1, Sector-62, Noida-201301, India \\ chhaya1974@rediffmail.com \\ ${ }^{2}$ National Physical Laboratory, DR K S Krishnan Road, New Delhi-110012, \\ India \\ mvprasademail.nplindia.ernet.in \\ ${ }^{3}$ C-DOT, Mandigaon Road, Opp. New Manglapuri, Chattarpur, Mehraulli, \\ New Delhi-110030, India \\ pdalela@gmail.com
}

\begin{abstract}
In this paper, tuning of COST-231 Hata prediction method has been carried out based on experiments at $2.3 \mathrm{GHz}$ using WiMAX transmissions conducted in western India. Fine tuning of the model is carried out using large number of measurement records to increase the accuracy of the prediction. The parameters of this model are tuned based on a linear iterative tuning method. The path loss predictions of tuned model are compared with the original COST-231 Hata model. Mean errors, standard deviation of error of tuned COST-231 Hata model has been deduced and compared with original COST-231Hata model. Mean error calculated by tuned model reduces by $14.3 \mathrm{~dB}$ and reduction of $3.5 \mathrm{~dB}$ is achieved in standard deviation of error. Root mean square error and coefficient of variation of tuned model are used to validate the tuning method. Root mean square error of tuned model reduces by $14.4 \mathrm{~dB}$ compared with the original COST-231 Hata model.
\end{abstract}

\section{KEYWORDS}

Pathloss, path loss exponent, propagation model, WiMAX

\section{INTRODUCTION}

The propagation model fine-tuning is one of the most important issues in efficient network planning. Technology specific radio network planning (RNP) is required to have guaranteed Quality of Services (QoS). The key aspects of RNP in a specific frequency band are coverage, capacity, QoS and interference. For specific equipment and frequency band, the propagation model is the key parameter for RNP. Propagation models are used extensively in network planning, particularly for conducting feasibility studies and performing initial system deployment. Recent developments in the telecom sector of India showing the Government's initiative for the coverage of rural and urban areas with broadband systems spurred lots of activity in the WiMAX systems based on IEEE 802.16 standard. In the WiMAX technology, spectrum managers in India are allocating either 2.3 or $3.5 \mathrm{GHz}$ band depending on availability. To determine characteristics

David C. Wyld, et al. (Eds): CCSEA, SEA, CLOUD, DKMP, CS \& IT 05, pp. 255-267, 2012.

(C) CS \& IT-CSCP 2012

DOI : $10.5121 /$ csit. 2012.2227 
of channel, testing of actual propagation model and tuning is required to obtain propagation model which reflects radio propagation characteristics exactly. Several kinds of popular radio network planning software as ASSET software of AIRCOM Company in England, PLANET software of MARCONI Company in England and ATOLL software of FOSK Company in France [1] are used for propagation model tuning.

Medeisis and Kajackas [2] presented the tuned Okumura Hata model in urban and rural zones at Lituania at 160, 450, 900 and $1800 \mathrm{MHz}$ bands. Prasad etal. has carried out tuning of COST-231 Hata model based on various data sets generated over various regions of India [3]. Mardeni \& Priya [4] presented optimized COST-231 Hata model to predict path loss for suburban and open urban environments in the $2360-2390 \mathrm{MHz}$ based as described in [5]. In [6], tuning method for COST-231 Hata model using least square theory is described which relates to many tuning parameters but the iterative tuning process is relatively complicated. Yang \& Shi [7] proposed a simple linear iterative tuning method and obtained an exact outdoor propagation model fitting for $3 \mathrm{G}$ system. A preliminary study on prediction methods involving seven base stations in dense urban region of Mumbai, India has been reported [8] in which COST-231 Hata gave comparatively good agreement with the measured data as compared to other models. COST-231 Hata is fit for forecasting path loss of great cell communication system in different city environment. Furthermore because this model adds a big city tuning parameter, when it is used to network planning for different types of cities, the anticipative effect can be achieved easily. So in this paper fine tuning of COST-231 Hata has been carried out and tuning parameters were deduced based on the approach of Yang and Shi [7]. The experimental data utilized in this study corresponds to $2.3 \mathrm{GHz}$ WiMAX radio measurements of seventeen base stations in mixed environments, carried out in western India. Statistical analysis of tuned COST-231Hata and original COST-231 Hata models also has been presented.

This paper is organized as follows. In Section II, experimental details have been provided. This is followed by description of tuning methodology in Section III. Results on statistical analysis and its validation are given in Section IV. Conclusions are presented in Section V.

\section{EXPERIMENTAL DETAILS}

\subsection{Equipment Description}

The details of the seventeen base stations are shown in Table I. The transmitting antenna used in the present study was the omni-directional antenna TW2.3/OMNI/8dB [9]. The transmitter used for experiment was Tortoise dual-band transmitter from Berkeley Varitronics Systems. The receiver used is Coyote dual-band receiver from Berkeley Varitronics System [10]. The averaging of 512 samples per second in temporal and spatial zone is carried out. The omni-directional receiver antenna with $2 \mathrm{dBi}$ gain was used for the present study. The calculated average received power has been used to estimate the path loss corresponding to each measurement.

\subsection{Environmental Details}

The collected data have been acquired in mixed environment of Mumbai city, India. The clutter diagram gives a feel of the environment. In the present study, mixed environment is divided in three categories. First category consists nine base stations; Asiana (AHN), Asmita Breeze (ATB), Indrapuri (IDP), Kshurjay (KSJ), Shroff tower (SFT), Sita Smruti (SST), Sarkar Plaza (SKR) \& Hare krishna (HKC), having partly dense urban, partly light dense urban and partly open with marginal coastal zones. All the nine sites are situated in urban area of Mumbai, India, as shown 
in Fig. 1. The clutter environments of these sites are shown in different colors in the legend of Fig. 1.

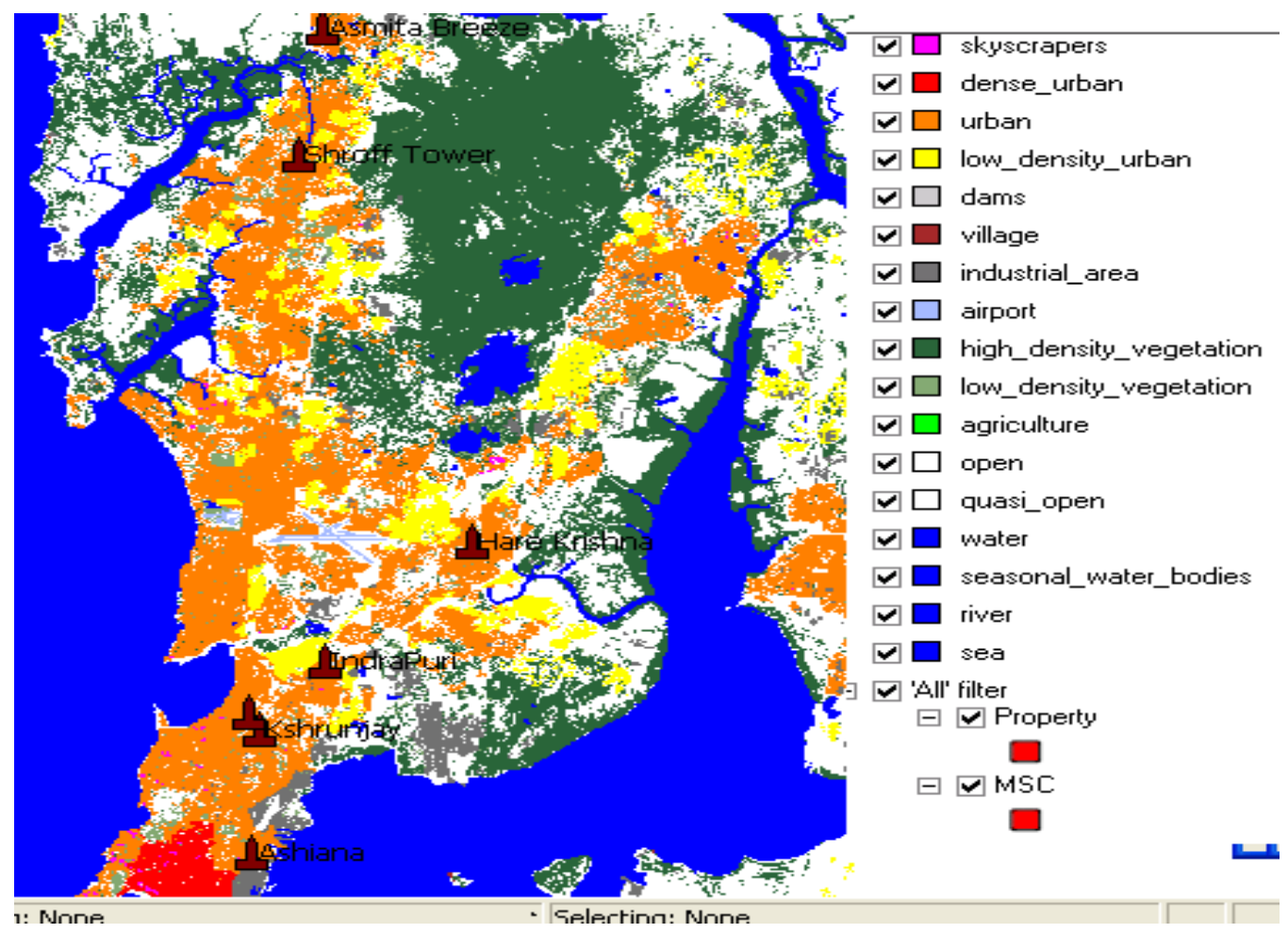

Fig.1 Clutter environment for experimental sites (AHN, ATB, IDP, KSJ, SFT, SST, SKR, HKC)

AHN is surrounded by skyscraper buildings at southern and western sides, while, on eastern side, it has coastal environment which starts at $0.8 \mathrm{~km}$ from AHN base station. ATB base station lies in dense urban region and from $0.2 \mathrm{~km}$ onwards from the base station, the region comes under open category. Northern and western sides have open region start from $.2 \mathrm{~km}$ and $0.4 \mathrm{~km}$ respectively from the ATB base station. IDP is fully urban in nature, which is surrounded by open regions up to small distances in southern and eastern side. KSJ lies in urban region with skyscrapers at short distances. SFT Base station lies in dense urban region and is surrounded by light dense urban up to $0.6 \mathrm{~km}$ in eastern side. Coastal zone starts at $0.7 \mathrm{~km}$ from the SFT base station. SST base station is also surrounded by light dense urban environment up to small distances. HKC lie in urban region and the region extending $1.2 \mathrm{~km}$ east side and $0.6 \mathrm{~km}$ north side from HKC base station is open area. Eastern side of SKR is coastal zone which starts at $.6 \mathrm{~km}$ from base station SKR and southern side has skyscrapers at $0.6 \mathrm{~km}$ from base station.

The second category is partly urban, partly open, partly low density vegetation. Low density vegetation consists of residential environment mixed with trees. The following stations come under this category; Konark darshan (KKD), Sahara Plaza (SP), Vertex Vikas (VXV), Newgreen Lawn (NGL), Crystal tower (CTL) and Pinki Cinema (PKY), as shown in Fig. 2.

KKD base station lies in urban region and is surrounded by low density vegetation environment up to small distances. The region around the base station SP is low density vegetation. VXV is fully surrounded by urban environment and low density vegetation is present towards south side 
after $0.2 \mathrm{~km}$ from VXV base station site. NGL lies in urban region and surrounded by open area. CTL is having varying tree density with irregular terrain in North-East direction start from $0.2 \mathrm{~km}$ from CTL base station.

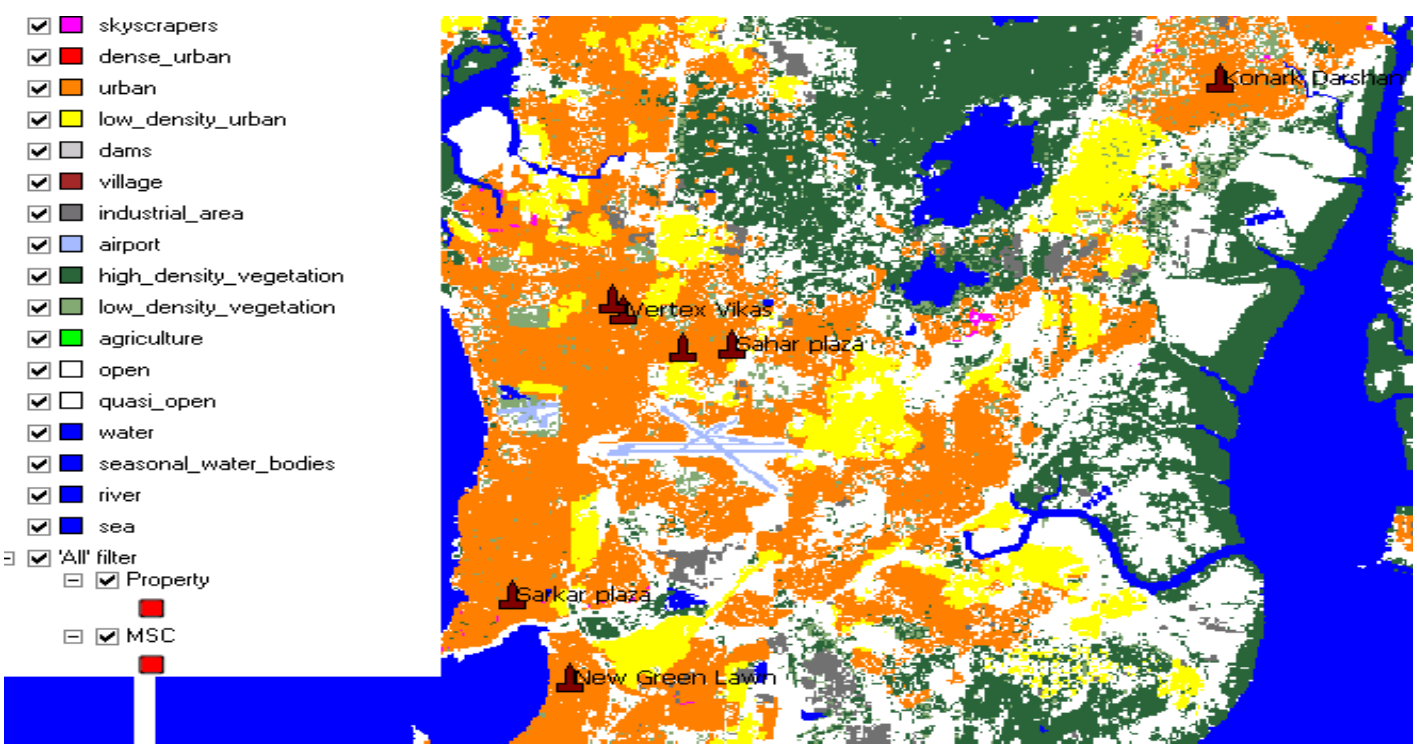

Fig. 2 Clutter environment for experimental sites: Konark darshan (KKD), Sahara Plaza (SP), Vertex Vikas (VXV), Newgreen Lawn (NGL), Crystal tower (CTL) and Pinki Cinema (PKY)

PKY is surrounded by low density urban environments at eastern side and western sides at $0.2 \mathrm{~km}$ and $0.7 \mathrm{~km}$ from base station respectively. Base stations in third category are partly urban, partly light dense urban and partly industrial zone. The base station includes in this category are Virkrupa (VKP), Voltas (VLT) and Lily Apartments (LYA), as shown in Fig. 3. 


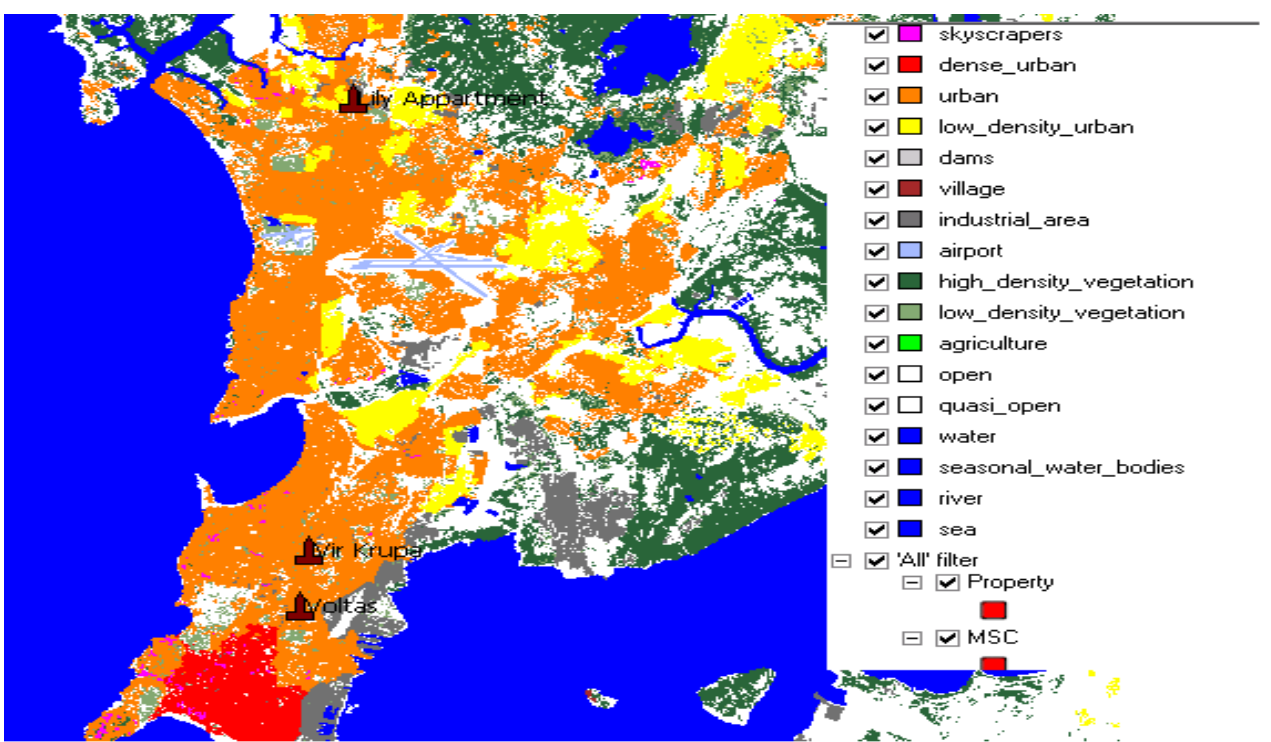

Fig. 3 Clutter environment for experimental sites: Virkrupa (VKP), Voltas (VLT) and Lily Apartments (LYA).

VKP lies in urban region with industrial zone appear in eastern side of VKP base station at 0.3 $\mathrm{km}$. Industrial area covers entire eastern side of VLT base station. LYA lie in urban region with northern and southern - eastern side industrial region and western side of LYA base station is light dense urban.

\section{Methodology}

\subsection{COST-231 Hata Model}

This is an extension of Okumura-Hata model, applicable for frequencies from 1.5 to $2 \mathrm{GHz}$, with receiving antenna heights up to $10 \mathrm{~m}$ and transmitting antenna heights of $30-200 \mathrm{~m}$ [11]. It is used for prediction of path loss for mobile wireless system in urban environments. COST231Hata model contains corrections for urban, suburban and rural (flat) environments [12]. Although its frequency range is outside that of our measurements, its simplicity and the availability of correction factors has allowed us to use it for path loss prediction at this frequency. Furthermore, this model is the basis for the Standard Propagation Model which is used for path loss modelling in WiMAX systems [13].

The basic equation for the path loss in $\mathrm{dB}[14]$ is

$$
\begin{aligned}
& P L=46.3+33.9 \log f-13.82 \log h_{t}-a\left(h_{r}\right)+ \\
& \left(44.9-6.55 \log h_{t}\right) \log d+c_{m}
\end{aligned}
$$

where $f$ is the frequency in $\mathrm{MHz}, d$ is the distance between transmitting and receiving antennas in $\mathrm{km}, h_{t}$ is the transmitting antenna height above ground level in meters (m). The correction factor $c_{m}$ is defined as $0 \mathrm{~dB}$ for suburban or open environments and $3 \mathrm{~dB}$ for urban environment. The term $a\left(h_{r}\right)$ is defined for urban and suburban environments respectively as 
$a\left(h_{r}\right)=3.2\left(\log 11.75 h_{r}\right)^{2}-4.97 f \geq 400 M H z$

$a\left(h_{r}\right)=1.1(\log f-0.7) h_{r}-(1.56 \log f-0.8)$.

where $h_{r}$ is the receiving antenna height above ground level.

For sites having partly dense urban, partly light dense urban and partly open with marginal coastal zones and sites having partly urban, partly light dense urban and partly industrial zone, path loss is calculated using (1) and (3) with $c_{m}$ value $3 \mathrm{~dB}$ whereas sites with partly urban, partly open, partly low density vegetation, path loss is calculated using (1) and (3) with $c_{m}$ value $0 \mathrm{~dB}$.

\subsection{Tuning Methodology}

Due to the different characteristics of the environment for which the models have been made, a tuning procedure is needed to adjust model parameters to the measured data. The approach given by Yang and Shi [7] has been utilized in the present study. It is given as [15]

$L=K_{1}+K_{2} \log d+K_{3} \log h_{t e}+K_{4} \log h_{t e} * \log d+K_{5} \log f-a\left(h_{r e}\right)$

where $K_{1}$ to $K_{5}$ are model tuning parameters, $d$ is the distance between transmitting and receiving antennas in $\mathrm{km}, h_{t}$ is the transmitting antenna height above ground level in meters (m), $f$ is the frequency in $\mathrm{MHz}, h_{r}$ is the receiving antenna height above ground level in meters and $a\left(h_{r}\right)$ is same as above. For each test of a certain station, $f, h_{r}$ are all fixed value except $\mathrm{d}$ so the tuning aims for $K_{1} \& K_{2}$. An attempt has been made to tune the value of $K_{1} \& K_{2}$ with the help of measured results. The accuracy of the prediction model in different environments can be improved by proper tuning of these two parameters. The path loss formula of tuned propagation model is written as [7]

$$
\begin{aligned}
L & =K_{1}+K_{2} \log d+K_{3} \log h_{t e}+K_{4} \log h_{t e} * \log d+K_{5} \log f-a\left(h_{r e}\right)+C_{1}+C_{2}+\log d \\
& =\left(K_{1}+C_{1}\right)+\left(K_{2}+C_{2}\right) \log d+K_{3} \log h_{t e}+K_{4} \log h_{t e} * \log d+K_{5} \log f-a\left(h_{r e}\right) \ldots \ldots \ldots . .
\end{aligned}
$$

where $K_{1}+C_{1}$ is the $K_{1}$ after model tuning, $K_{2}+C_{2}$ is the $K_{2}$ after model tuning and $K_{1}, K_{2}$, $K_{3}$ keep their values in COST231Hata model unchangeable. The parameters $C_{1}$ and $C_{2}$ are calculated from [7].

\section{RESULTS}

Using above stated approach tuned parameters $C_{1}$ and $C_{2}$ for the above base stations have been deduced and depicted in Table II. Apart from $\mathrm{C}_{1}$ and $\mathrm{C}_{2}$, Table II consists of $\mathrm{K}_{1}+\mathrm{C}_{1}$ and $\mathrm{K}_{2}+\mathrm{C}_{2}$ where $\mathrm{K}_{1}$ and $\mathrm{K}_{2}$ are the original parameters of COST231Hata model. Here for first category, $\mathrm{C}_{1}$ varies from 1.9 to 19.9 and $C_{2}$ carries value from -8.2 to -0.7 except SKR base station having $\mathrm{C}_{2}$ value 2.1. Taking into account the low density vegetation for second category, $\mathrm{C}_{1}$ varies from 5.7 to 16.1 and $\mathrm{C}_{2}$ lies in 2.3 to 14.0 range, except $\mathrm{KKD}$ with $\mathrm{C}_{2}$ is -4.6 . This may be due to low density vegetation which is surrounded KKD base station up to small distances from all sides. For the base stations which lie in partly urban, partly light dense urban, partly industrial zone, $\mathrm{C}_{1}$ varies from 2.2 to 7.9 and $\mathrm{C}_{2}$ has the value 3.7 and 6.4 for VLT and LYA respectively whereas 
for VKP $\mathrm{C}_{2}$ has the value -1.0 because of open environment in south and industrial region in eastern direction.

\subsection{Validation of Tuned Results}

The measured path losses have been compared with those deduced from classical COST-231 Hata model and tuned COST-231 Hata model. Typical figures corresponding to each category are shown in Figs. 4-6. The remaining figures are not shown due to lack of space.

Analysis of Mean prediction error, error's standard deviation, root mean square error (RMSE) and coefficient of variation ( measure of how well the fitted curve represents the data), for tuned COST-231Hata and original COST-231Hata model have been done using (6), (7), (8) and (9) as shown in Table II.

$$
\begin{aligned}
& \text { MeanError }=\frac{1}{M} \sum_{i=1}^{M}\left|y_{i}-\hat{y}_{i}\right| \\
& \text { Error'sStandardDeviainn }=\sqrt{\frac{1}{M} \sum_{i=1}^{M}\left(y_{i}-\hat{y}_{i} \mid- \text { MeanErro }\right)^{2}} \text {. } \\
& R M S E=\sqrt{\frac{1}{M} \sum_{i=1}^{M}\left|y_{i}-\hat{y}_{i}\right|^{2}} \\
& \text { Coeff. OfVariation }=1-\frac{\sum_{i=1}^{M}\left(y_{i}-\hat{y}_{i}\right)^{2}}{\sum_{i=1}^{M}\left(y_{i}-\bar{y}_{i}\right)^{2}} \text {. }
\end{aligned}
$$

where $\hat{y}_{i}$ denotes the predicted value of data $y_{i}, \bar{y}_{i}$ is the mean of measured data and $\mathrm{M}$ is the number of observations taken.

From Table II, the following observations have been made.

In the first category, the path loss predicted by tuned model follows the measured path loss closely (Fig. 4) and mean error reduces $0.4-14.3 \mathrm{~dB}$ from original COST-231 Hata. This large variation in prediction error of tuned model may be due to presence of open environment with coastal area in low density urban area. In our analysis error' standard deviation lies in the range of $3.8-5.3 \mathrm{~dB}$, less as compared to standard deviation range $4.4-8.4 \mathrm{~dB}$ of classical COST-231 Hata model. Error's standard deviation reduces up to $3.5 \mathrm{~dB}$ for SFT base station. Mardeni \& Riya [4] found the standard deviation of error ranges from $0.3-4.3 \mathrm{~dB}$ and $1.1-4.2 \mathrm{~dB}$ at distances ranging from $100 \mathrm{~m}$ to $1000 \mathrm{~m}$ for receiver antenna height $2 \mathrm{~m}$ and $4 \mathrm{~m}$ respectively for suburban environment. RMS errors have obtained a maximum improvement of about $14.4 \mathrm{~dB}$ for SFT base station and a minimum improvement around $0.4 \mathrm{~dB}$ for IDP base station. RMSE for tuned model ranges from $6.6-9.2 \mathrm{~dB}$ whereas for original COST-231 Hata model this range is $6.9-21.3 \mathrm{~dB}$. For SST base station, tuned model implies that about $70 \%$ of the total variation in the measured data can be explained by the linear relationship between the estimated and measured data whereas only $30 \%$ of the measured data are explained using the classical COST231 Hata model. For the rest seven base stations, coefficient of variation of tuned model varies from $60.0 \%-80.0 \%$. 
For second category, reduction in mean error ranges from $0.9-12.5 \mathrm{~dB}$ and maximum reduction of $2.8 \mathrm{~dB}$ is achieved for error's standard deviation of COST-231 Hata model. Error' standard deviation lies in the range of $4.1-6.1 \mathrm{~dB}$, less as compared to standard deviation range $4.8-7.5$ $\mathrm{dB}$ of original COST-231 Hata model. Yang \& Shi gave the reduction in error's standard deviation compared with classical COST-231 Hata model of $0.03 \mathrm{~dB}$ for suburban and medium sized cities. Mardeni \& Riya [4] found the standard deviation of error ranges from $0.3-4.3 \mathrm{~dB}$ and $1.1-4.2 \mathrm{~dB}$ at distances ranging from $100 \mathrm{~m}$ to $1000 \mathrm{~m}$ for receiver antenna height $2 \mathrm{~m}$ and $4 \mathrm{~m}$ respectively for suburban environment. Reduction in RMSE from 1.6 -10.8 dB is achieved by tuning of model. Coefficient of variation of classical COST231Hata model is $0.1-0.4 \mathrm{~dB}$ whereas after tuning it increases $0.5-0.7 \mathrm{~dB}$.

For third category, mean prediction error is reduced by $0.3-3.4 \mathrm{~dB}$ and reduction in error's standard deviation compared with classical COST231Hata model is up to $1.2 \mathrm{~dB}$ is achieved. Error's standard deviation ranges from $4.5-5.6 \mathrm{~dB}$ for original COST-231 Hata whereas for tuned model this ranges from 4.2 - 5.1 dB. RMSE for tuned model varies from $7.1-8.2 \mathrm{~dB}$ whereas classical model has $8.1-10.7 \mathrm{~dB}$. VKP base station, tuned model implies that about $90 \%$ of the total variation in the measured data can be explained by the linear relationship between the estimated and measured data whereas only $40 \%$ of the measured data are explained using the original COST-231 Hata model. It can be seen from Table II that the mean prediction error, error's standard deviation, RMSE of the tuned model are all less than the original COST-231Hata model. This above discussion indicates that the prediction of tuned model has more accuracy towards the measurements as compared to original COST-231 Hata model.

\section{CONCLUSION}

An experimental campaign was conducted in the urban, coastal, industrial region of Mumbai using WiMAX OFDM transmissions at $2.3 \mathrm{GHz}$, for seventeen base stations. A linear-iterative tuning method using least square theory is used to tune COST-231Hata propagation model in terrain having partly dense urban, partly light dense urban, partly open with marginal coastal zones; partly urban, partly open, partly low density vegetation environment and partly urban, low density urban, industrial environment. Optimally tuned values of $K_{1}$ and $K_{2}$ are deduced for best matching between the measured and tuned path loss values and it shows the ability of the tuned model in the reduction of the prediction error. This demonstrates that the tuning of $\mathrm{K}_{1}$ and $\mathrm{K}_{2}$ parameters can be effectively utilized for predicting the network plan closer to the actual scenario. Mean errors, error's standard deviation, root mean square error and coefficient of determination of tuned model is deduced and compared with classical COST-231 Hata. It is shown that average error of predicted data, error's standard deviation and RMSE, calculated by tuned model reduces up to $14.3 \mathrm{~dB}, 3.5 \mathrm{~dB}$ and $14.4 \mathrm{~dB}$ respectively and up to $90 \%$ of the total variation in the measured data can be explained by the linear relationship between the tuned and measured data which accords with the requirement of mobile communication. The tuned model shows high accuracy and is able to predict path loss with small standard deviation as compared to original COST-231 Hata model. Also, these results can be utilized to predict the signal level, path losses in these regions and can be compared to future datasets which will be generated in this region at various frequencies.

\section{REFERENCES}

[1] Liu Yang, Wand Fang and Chang Yongyu, YANG Dacheng (2007) "Theoretical and Simulation Investigation on Coexistence between TD-SCDMA and WCDMA system," Vehicular Technology Conference, IEEE, Dublin, pp.1198-1203. 
[2] Medeisis and A. Kajackas (2000) "On the Use of the Universal Okumura-Hata Propagation Prediction Model in Rural Areas", Vehicular Technology Conference, IEEE, vol. 3, pp. 815- 1818, Tokyo, Japan.

[3] M V S N Prasad etal. (2008) “ Terrestrial Communication Experiments over Various Regions of India Subcontinent and Tuning of Hata's Model,” Annals Telecommunication, vol. 63, pp. 223-235.

[4] Mardeni.R, T. Siva Priya (2010) "Optimize Cost231 Hata models for Wi-MAX pathloss prediction in Suburban and open urban Environments," Canadian Center Of Science and Education, vol. 4, no. 9, pp. 75-89.

[5] Jacques, L. \& Michel, S (2000) "Radio Wave Propagation Principles and Techniques," John Wiley \& sons Ltd., 2000.

[6] Chen Bo, Shi Wenxiao and Yang Mingjing (2008) "Study on Propagation Model Tuning Based on WCDMA System,” Journal of Jilin University (Information Science Edition), Jilin University Press, Changchun, pp.38-43, Changchun, China.

[7] M. Yang, W. Shi (2008) "A Linear least Square Method of propagation model tuning for 3G Radio Network Planning”, Fourth International Conference on Natural Computation ICNC, Jinan, pp. 150154.

[8] Chhaya Dalela etal. (2010) "A Preliminary Analysis of WiMAX Radio Measurements at $2.3 \mathrm{GHz}$ over Western India” 6th International Conference Of Microwaves, Antenna and Propagation, and Remote Sensing, Jodhpur, India .

[9] “Omni antenna," Twin Antennas Vadodara, Vadodara, India [Online]. Available: http://www.twinantennas.com/omni-antenna.html\#2-3ghz-omni-antenna

[10] "Berkeley Varitronics Systems," Berkeley Varitronics Systems, Inc., Metuchen, NJ [Online]. Available: http://www.bvsystems.com

[11] Hata, M. (1981) "Empirical formula for propagation loss in land mobile radio services," IEEE Transactions on Vehicular Technology, vol. VT-29, pp. 317-325.

[12] Abhayawardhana, V. S., Wassell, I. J., Crosby, D., Sellars M.P. \& Brown, M.G. (2005) “Comparison of empirical propagation path loss models for fixed wireless access systems" Proceedings of IEEE Conference on Vehicular Technology, Sweden, Vol. 1, pp 73-77.

[13] Asztalos, T (1999) "Planning a WiMAX Radio Network with A9155. Alcatel-Lucent COST Action 231. Digital mobile radio towards future generation systems," final report, tech. rep., European Communities, EUR 18957.

[14] J. D. Parsons (1998) The mobile radio propagation Channel. New York: Wiley.

[15] Luo Shuwan, Yang Geng ( 2007). "Propagation Model Tuning of TD-SCDMA", Guangdong Communication Technology, Guangdong Telecommunication Press, pp.37-41 


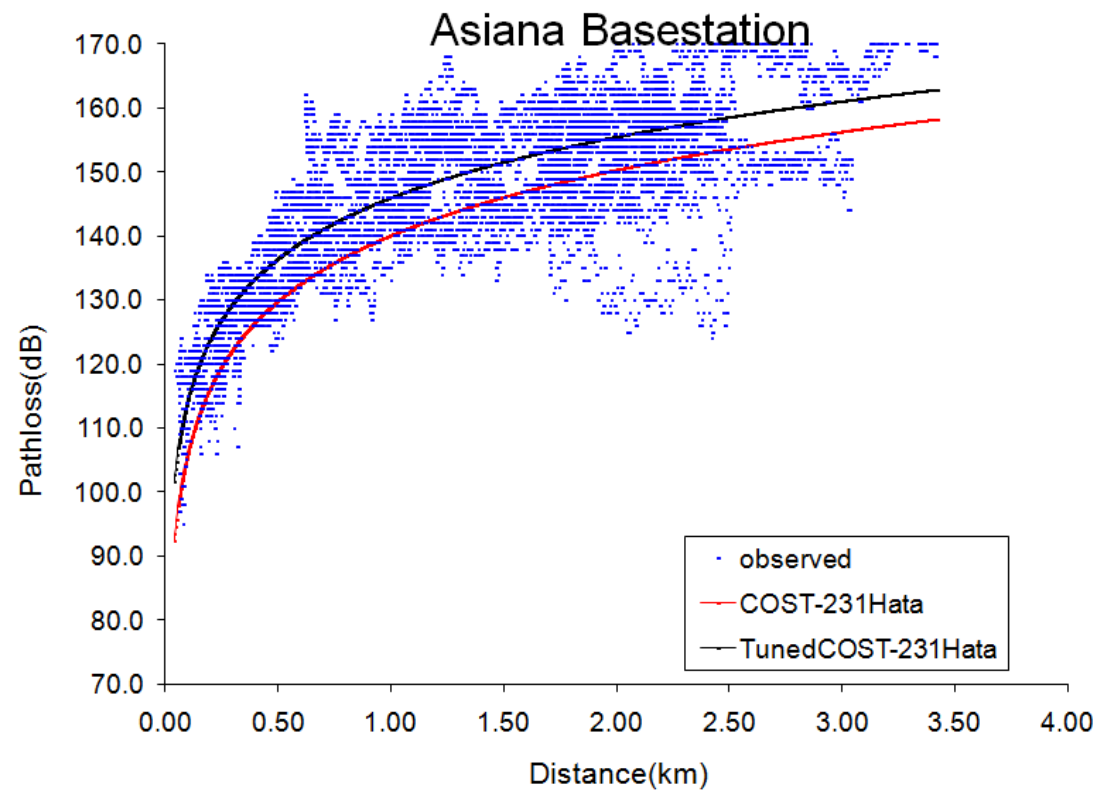

Fig. 4. Comparison of tuned model predicted losses with the measurements and the COST-231 Hata model for AHN Base station

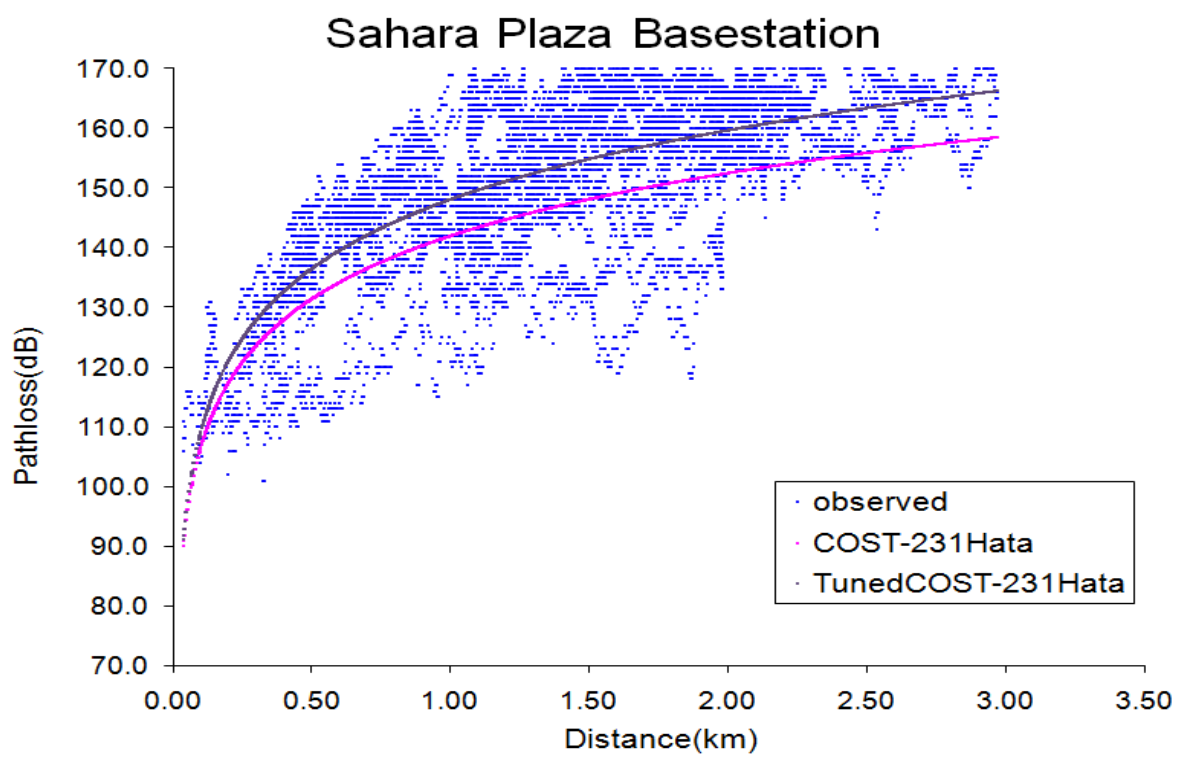

Fig. 5. Comparison of tuned model predicted losses with the measurements and the COST-231 Hata model for SP Base station 


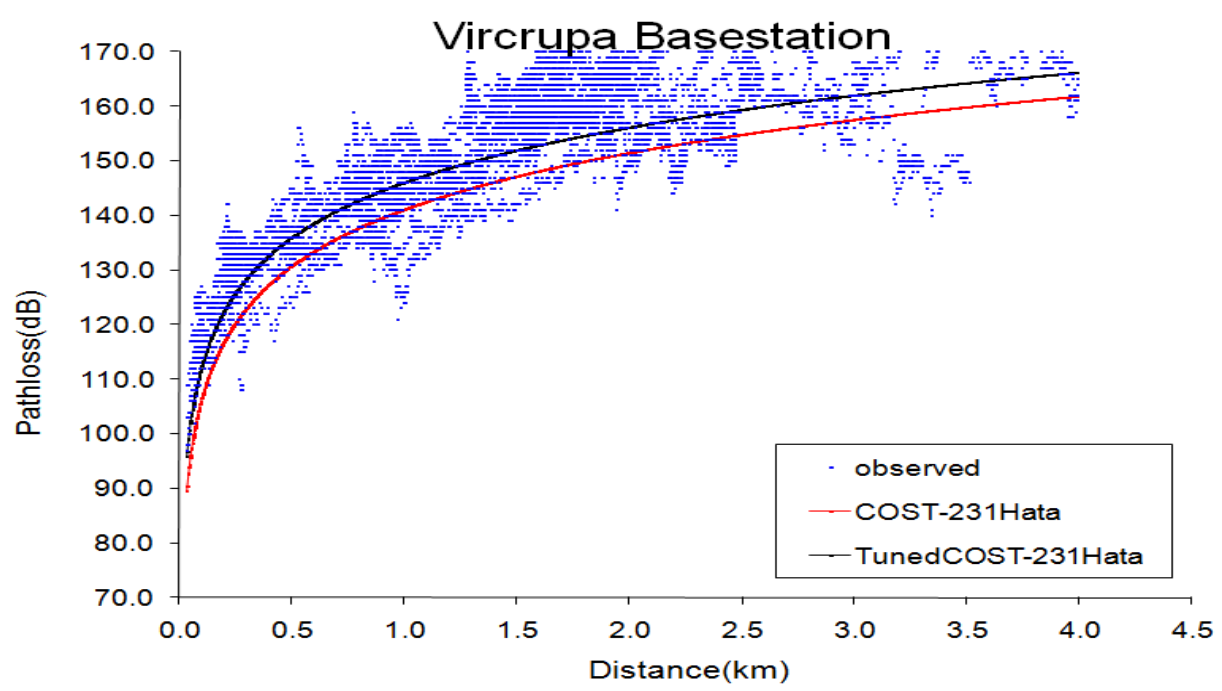

Fig.6. Comparison of tuned model predicted losses with the measurements and the COST-231 Hata model for VKP Base station

TABLE I

Experimental Details and Tuned Parameters Of Seventeen Base Stations

\begin{tabular}{|c|c|c|c|c|c|c|}
\hline \multirow[t]{2}{*}{ Categories } & \multirow[t]{2}{*}{ Sites Name } & \multirow{2}{*}{$\begin{array}{l}\text { Height of transmitting } \\
\text { antenna }(\mathrm{m})\end{array}$} & \multicolumn{4}{|c|}{ Tuned Parameters } \\
\hline & & & $\mathrm{C}_{1}$ & $\mathrm{C}_{2}$ & $\mathrm{~K}_{1}+\mathrm{C}_{1}$ & $\mathrm{~K}_{2}+\mathrm{C}_{2}$ \\
\hline \multirow{8}{*}{ First Category } & Asiana(AHN) & 47 & 5.9 & -2.4 & 52.2 & 42.5 \\
\hline & Asmita Breeze(ATB) & 31 & 4.5 & -2.1 & 50.8 & 42.8 \\
\hline & Indrapuri(IDP) & 27 & 1.9 & -6.0 & 48.2 & 38.9 \\
\hline & Kshurjay(KSJ) & 27 & 5.4 & -7.6 & 51.7 & 37.3 \\
\hline & Shroff tower(SFT) & 31 & 19.9 & -8.2 & 66.2 & 36.7 \\
\hline & Sita Smruti(SST) & 36 & 8.5 & -3.8 & 54.8 & 41.1 \\
\hline & Hare Krishna(HKC) & 37 & 11.6 & 2.1 & 57.9 & 47.0 \\
\hline & Sarkar Plaza(SKR) & 35 & 16.8 & -0.7 & 63.1 & 44.2 \\
\hline \multirow{6}{*}{ Second Category } & Konark Darshan & 39 & 8.4 & -4.6 & 54.7 & 40.3 \\
\hline & Sahara Plaza(SP) & 34 & 9.2 & 3.5 & 55.5 & 48.4 \\
\hline & Vertex Vikas(VXV) & 33 & 11.9 & 9.6 & 58.2 & 54.5 \\
\hline & New Green lawn(NGL) & 34 & 9.2 & 2.3 & 55.4 & 42.6 \\
\hline & Crystal Tower(CTL) & 32 & 16.1 & 6.6 & 62.4 & 51.5 \\
\hline & Pinki Cinema(PKY) & 35 & 5.7 & 14.0 & 52.0 & 58.9 \\
\hline \multirow{3}{*}{ Third category } & Vircrupa(VKP) & 40 & 7.9 & -1.0 & 54.2 & 43.9 \\
\hline & Voltas(VLT) & 46 & 2.9 & 3.7 & 49.2 & 48.6 \\
\hline & Lily Apartments(LYA) & 36 & 2.2 & 6.4 & 48.5 & 51.3 \\
\hline \multicolumn{2}{|c|}{ Height of receiving antenna } & $1.5 \mathrm{~m}$ & \multirow{5}{*}{\multicolumn{2}{|c|}{$\begin{array}{l}\text { Parameters before } \\
\text { tuning/after tuning }\end{array}$}} & $\mathrm{K}_{1}$ & 46.3 \\
\hline \multicolumn{2}{|c|}{ Transmitted power } & $43 \mathrm{dBm}$ & & & $\mathrm{K}_{2}$ & 44.9 \\
\hline \multicolumn{2}{|c|}{ Average Height of building } & $25 \mathrm{~m}$ & & & $\mathrm{~K}_{3}$ & -13.82 \\
\hline \multicolumn{2}{|c|}{ Average street width } & $15 \mathrm{~m}$ & & & $\mathrm{~K}_{4}$ & -6.55 \\
\hline \multicolumn{2}{|c|}{ Average separation between buildings } & $30 \mathrm{~m}$ & & & $\mathrm{~K}_{5}$ & 33.9 \\
\hline
\end{tabular}


TABLE II

Comparison of Statistical Parameters of COST-231Hata and Tuned COST-231Hata Model

\begin{tabular}{|c|c|c|c|c|c|c|}
\hline \multirow[t]{2}{*}{ Categonies } & \multirow[t]{2}{*}{ Sites Name } & \multirow{2}{*}{$\begin{array}{l}\text { Height of transmitting } \\
\text { antenna (m) }\end{array}$} & \multicolumn{4}{|c|}{ Tuned Parameters } \\
\hline & & & $\mathrm{C}_{1}$ & $\mathrm{C}_{2}$ & $\mathrm{~K}_{1}+\mathrm{C}_{1}$ & $\mathrm{~K}_{2}+\mathrm{C}_{2}$ \\
\hline \multirow{8}{*}{ First Category } & Asiana(AHN) & 47 & 5.9 & -2.4 & 52.2 & 42,5 \\
\hline & Asmita Brezze(ATB) & 31 & 4.5 & -2.1 & 50.8 & 42.8 \\
\hline & Indrapuri(IDP) & 27 & 1.9 & -6.0 & 48.2 & 38.9 \\
\hline & Kshurjay(KSJ) & 27 & 5.4 & -7.6 & 51.7 & 37.3 \\
\hline & Shroff tower(SFT) & 31 & 19.9 & -8.2 & 66.2 & 36.7 \\
\hline & Sita Smruti(SST) & 36 & 8.5 & -3.8 & 54.8 & 41.1 \\
\hline & Hare Krishna(HKC) & 37 & 11.6 & 2.1 & 57.9 & 47.0 \\
\hline & Sarkar Plaza(SKR) & 35 & 16.8 & -0.7 & 63.1 & 44.2 \\
\hline \multirow{6}{*}{ Second Category } & Konark Darshan & 39 & 8.4 & -4.6 & 54.7 & 40.3 \\
\hline & Sahara Plaza(SP) & 34 & 9.2 & 3.5 & 55.5 & 48.4 \\
\hline & Vertex Vikas(VXV) & 33 & 11.9 & 9.6 & 58.2 & 54.5 \\
\hline & New Green lawn(NGL) & 34 & 9.2 & 2.3 & 55.4 & 42.6 \\
\hline & Crystal Tower(CTL) & 32 & 16.1 & 6.6 & 62.4 & 51.5 \\
\hline & Pinki Cinema(PKY) & 35 & 5.7 & 14.0 & 52.0 & 58.9 \\
\hline \multirow{3}{*}{ Third category } & Vircrupa(VKP) & 40 & 7.9 & -1.0 & 54.2 & 43.9 \\
\hline & Voltas(VLT) & 46 & 2.9 & 3.7 & 49.2 & 48.6 \\
\hline & Lily Apartments(LYA) & 36 & 2.2 & 6.4 & 48.5 & 51.3 \\
\hline \multicolumn{2}{|c|}{ Height of receiving antenna } & $1.5 \mathrm{~m}$ & \multirow{5}{*}{\multicolumn{2}{|c|}{ Parameters before tuning/after tuning }} & $K_{1}$ & 46.3 \\
\hline \multicolumn{2}{|c|}{ Transmitted power } & $43 \mathrm{dBm}$ & & & $\mathrm{K}_{2}$ & 44.9 \\
\hline \multicolumn{2}{|c|}{ Average Height of building } & $25 \mathrm{~m}$ & & & $\mathrm{~K}_{3}$ & -13.82 \\
\hline \multicolumn{2}{|c|}{ Average street width } & $15 \mathrm{~m}$ & & & $\mathrm{~K}_{4}$ & -6.55 \\
\hline \multicolumn{2}{|c|}{ Average separation between buildings } & $30 \mathrm{~m}$ & & & $\mathrm{~K}_{5}$ & 33.9 \\
\hline
\end{tabular}




\section{Authors}

Chhaya Dalela received the B.Tech. degree in Electronics Engg. from H.B.T.I.,Kanpur in 1995, M.Tech. in Digital Communication from U.P.T.U.,Lucknow, and currently pursuing Ph.D. in channel characterisation and modelling. Presently, she is working with JSS Academy of Technical Education, Noida, as Assistant Professor in Electronics Engineering Department.

Dr M V S N Prasad is presently working as a scientist in National Physical Laboratory. His research areas are radio channel measurements and modeling for mobile and fixed communications, mobile commnications in railway tunnels, microwave propagation, rad iowave propagation related to broadcasting etc. He has developed active links with various user organizations in the area of telecommunications like VSNL, Railways,Dept. of of Telecommunications, three wings of defense and rendered consultancy services in these areas and established collaborations with many universities. He received the URSI young scientist award

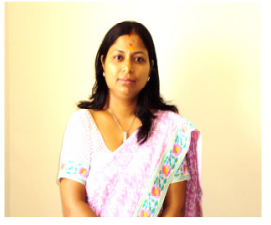
in 1990, Best paper award from National Space Science Symposium in 1990, Best paper award from Broadcast engineering society( India) in 1998 and 2001. Elected as a member of American Geophysical union under the Lloyd V.Berkner fund. He participated in telecommunication and radio wave propagation workshops at the International centre for theoretical physics, Trieste, Italy. He has published several papers in national and international journals and acted as a reviewer for many journals in this field.

Dr. Pankaj Kumar Dalela obtained B.Tech (Electronics Engineering) from H.B.T.I., Kanpur in 1993, M.Tech. (Microwave Engineering) and Ph.D. from I.T.B.H.U.,Varanasi in 1996 and 2008 respecti vely. Currently he is working as Group Leader in C-DOT, Delhi, a premier telecom research center of government of India. He received the URSI young scientist award in 2005. His areas of research interest are channel measurements and modeling for broadband communications, Cognitive Radio, Algorithm development, Telecommunication network planning etc. He has published more than 50 research papers in national and international journals and

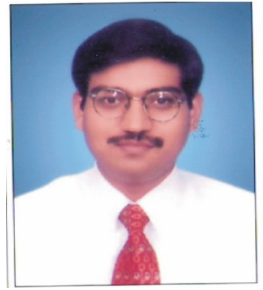
conference proceedings. 